\title{
In Situ Nuclear Characterization Infrastructure
}

\author{
FIIW 2011
}

\author{
James A. Smith \\ J. Rory Kennedy
}

November 2011

The INL is a

U.S. Department of Energy

National Laboratory

operated by

Battelle Energy Alliance

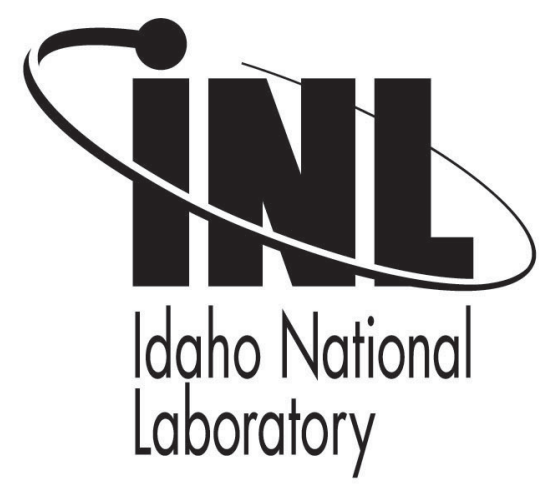

This is a preprint of a paper intended for publication in a journal or proceedings. Since changes may be made before publication, this preprint should not be cited or reproduced without permission of the author. This document was prepared as an account of work sponsored by an agency of the United States Government. Neither the United States Government nor any agency thereof, or any of their employees, makes any warranty, expressed or implied, or assumes any legal liability or responsibility for any third party's use, or the results of such use, of any information, apparatus, product or process disclosed in this report, or represents that its use by such third party would not infringe privately owned rights. The views expressed in this paper are not necessarily those of the United States Government or the sponsoring agency. 


\title{
In Situ Nuclear Characterization Infrastructure
}

\author{
Evolve Microstructure With A Prescribed In Situ Process
}

\author{
James A. Smith, J. Rory Kennedy \\ Fundamental Fuel Properties \\ Idaho National Lab \\ Idaho Falls, ID USA \\ James.Smith@INL.gov
}

\begin{abstract}
To be able to evolve microstructure with a prescribed in situ process, an effective measurement infrastructure must exist. This interdisciplinary infrastructure needs to be developed in parallel with in situ sensor technology. This paper discusses the essential elements in an effective measurement infrastructure.
\end{abstract}

Keywords- infrastructure; microstructure; measurement; irradiation; sensing; controls; nuclear fuels

\section{INTRODUCTION}

Advancing the Nuclear Fuel Cycle and Next Generation Nuclear Power Plant requires enhancing our fundamental understanding of fuel and materials behavior under irradiation. An important yet challenging way to advance our understanding of irradiated fuels and materials during irradiation is to develop effective in situ sensors and measurement systems that focus on the theme microstructure evolution under irradiation. An initiative to develop an in-pile measurements infrastructure will synergistically link together multiple internal and external programs to execute the core mission of developing the materials science foundation for a predictive understanding and design of nuclear fuels.

Robust and accurate in pile measurements will be instrumental to developing and validating a computationally predictive multi scale understanding of nuclear fuel and materials. The sensing technology must enable the linking of fundamental micro-structural damage mechanisms to the macroscopic degradation of the fuel components through a detailed understanding of the complex microstructure evolution in a harsh irradiation environment. This in-pile measurement data will then significantly advance fuel science, modeling, fuel and material design, reduce reactor variability during operation and allow for the development of novel predictive control schemes.

The end goal of the interdisciplinary programs within the Fuel Cycle Research and Development (FCRD) Campaign is to develop revolutionary fuels and processes that increase the efficiency, lifetime and burn up of nuclear fuel. To achieve success in developing revolutionary fuel and processes will require the following iterative steps:

1. Develop fuel composition

2. Measure the microstructure evolution and effects on material properties

Work sponsored by Department Of Energy-Office of Nuclear Energy
3. Understand microstructure evolution within the reactor environment

4. Design and control the critical microstructure evolution process.

Having the right composition is necessary but not sufficient to ensure a more efficient fuel. An efficient fuel must also have the right microstructure within the reactor to perform properly. The start up and shut down time periods should be taken advantage to condition the fuel's microstructure. By modulating the reactors process parameters, microstructure may be modified or the rate of change may be reduced. The fuel microstructure can be evolved in a prescribed manner in situ during the start up, operation and shut down periods. Processing the fuel microstructure within the reactor will require in situ sensors and independent control capabilities within the reactor. Thus not only will the sensors and control processes need to be developed along with fuel composition, but the necessary measurement and control architecture must also be in place within the reactor to enable advance fuel development and advanced reactor operation.

To be successful in accomplishing effective in pile measurements and evolving microstructure, an interdisciplinary measurement infrastructure needs to be developed in parallel with key sensing technology. For the purposes of discussion in this paper, infrastructure is defined as systems, technology, procedures, and algorithms that may be necessary in the delivery of calibrated and robust measurement data from in-pile sensors to archival databases. The basic, fundamental architecture of any system's infrastructure determines how it functions and how flexible it is to meet future requirements. The critical path for the successful implementation of the all important sensing technology will not be the sensors themselves but the infrastructure to communicate data from a reactor to the outside world in a non-intrusive manner. This discussion gives a high level overview of potential infrastructure that can advance our understanding of irradiated fuels and materials. An effective in-pile measurements initiative will lead to an international program for sciencebased fuels research and development.

\section{MEASUREMENT INFRASTRUCTURE OVERVIEW}

The necessary interdisciplinary infrastructure to enable the understanding of microstructure under irradiation will be 
outlined. While sensors are certainly a critical component in the measurement infrastructure [1], the discussion in this paper will focus on broader higher level methodology that often gets overlooked until it is needed late in the design process. The goal is to have the measurement infrastructure in place before the sensors have been developed. In fact, the measurement infrastructure is designed to enable the development of the sensors.

The key enabling infrastructure development will be in communicating sensor data in a non-intrusive manner. The use of in situ power generators will allow for unprecedented flexibility in designing active communication and sensor technology. The key enabler to placing sensors and support systems into the reactor will be the ability to develop radiation hardened components. Once the radiation hardened measurement system has been designed and prototyped, the behavior and cross sensitivity to harsh environmental parameters within the core need to be tested and calibrated in a controlled environment. The proposed Separate Effects Testing Facility for Beginning of Life Studies (SETFBLS) would be ideal for separate effects testing of the newly designed sensors. A revitalized TREAT (Transient Reactor Test Facility) would help with separate effects testing and determine the dynamic and damage thresholds during dynamic events. The Advanced Test Reactor (ATR) National Scientific User Facility (NSUF) furnishes a unique test bed with controllable irradiation conditions that will enable users to conduct the needed exploratory and confirmatory experiments for sensor performance and irradiation effects. The availability of ATR provides the unique capability of tying all of the experimental measurements and investigations to a true fission environment.

Salient measures will be presented to keep the efforts focused on enabling the development of effective modeling and simulation techniques. The measures for initial focus will expediently enhance the knowledge of microstructure under irradiation and enable the development of predictive models. The resulting measured data can then be input into a feedback loop with Modeling and Simulation. Thus, the core mission of developing the materials science foundations for a predictive understanding and design of nuclear fuel can be enabled and validated. The combination of new real-time online sensors and greater fundamental understanding of fuel and materials behavior will allow for the development of novel and resilient control strategies.

\section{INFRASTRUCTURE COMPONENTS}

As stated before, the success of the measurements initiative will depend upon the measurement infrastructure that is in place to support the sensors. The means of communication from the in-pile sensors to instrumentation external of the reactor will dictate the effectiveness and efficiency of the measurement systems. In-situ power generators and radiation hardened components will be key to placing instrumentation within the reactor. The SETFBLS and TREAT facilities will be key in understanding the behavior and performance of the sensors as well as developing calibration processes for use in the reactor. The role of these facilities in meeting the focus of this paper is described in some detail later in this section When effective sensors have been developed, the resulting data will need to be integrated into a feedback loop with modeling/simulation and controls programs.

\section{A. Communication}

Although instrumented leads are an effective means to communicate data to the outside world, instrumented leads adversely change the measurement environment and are cumbersome to work with. Wireless concepts are being investigated [1]. Optical, ultrasonic, and RF/microwave communication systems are being considered. If the current technology proves to be impractical, these technologies should be reevaluated periodically as advances in high temperature ultrasonic transducers, RF/microwave antenna design and optics are being made.

\section{B. In situ Power Generators}

The use of in situ power generators will allow for unprecedented flexibility in designing active communication and sensor technology. There are at least three different technologies worth investigating for this application: 1) Ceramic thermo electric generators, 2) Infrared Frequency selective resonators and 3) Microwave transmission. The Idaho National Laboratory (INL) and has established expertise in these areas that can be leveraged for nuclear applications. The expertise developed in the Thermoelectric generator project under the Space Nuclear Systems \& Technology Division can be leveraged. Infrared frequency selective resonators for power are currently being developed at the INL under the National \& Homeland Security Division is another example. Microwave power transmission is a fairly open technology that would need to be adapted for these applications. Since the INL already has a vast amount of expertise and resources in the thermo electric generator and infrared frequency selective resonators, these areas would be an excellent opportunity for the INL.

\section{Radiation Hardened Components}

The key enabler to placing sensors and support systems into the reactor will be the ability to develop radiation-hardened components. The irradiated components will provide communication, power, and sensing capabilities. Materials, electronics, and optics will have to be developed to withstand the harsh reactor environment, and inter-laboratory collaboration will likely be required.

\section{SETFBLS}

Once the radiation-hardened measurement system has been designed and prototyped, the behavior and cross sensitivity to harsh environmental parameters within the core need to be tested and calibrated in a controlled environment. The SETFBLS (Separate Effects Testing Facility for Beginning of Life Studies) [2-3] can provide this measurement development and calibration capability. The SETFBLS chamber would allow critical separate-effects capability for the development of in-pile instrumentation, which will significantly shorten the development timeline for sensor advances.

The SETFBLS facility provides not only separate-effects to understand the impact of irradiation variables on the instrumentation but also allows for "elbow room" that this type 
of work requires. SETFBLS has a line-of-sight capability and a large supporting volume around the irradiation area -- both of which are of considerable value in making measurements on novel systems and components. The availability of SETFBLS and its "ease of use" are also important for turn-around reasons. ATR is a great tool but has limitations on what you can put in (size and amount) and an inflexible/complex irradiation environment (not separate effects).

\section{E. TREAT}

TREAT (Transient Reactor Test Facility) [4-5] is an aircooled thermal test facility designed to evaluate reactor fuels and structural materials for transient overpower and undercooling conditions. TREAT is a dynamic nuclear reactor designed to provide testing to quantify fuel safety and qualify new fuel designs. The TREAT reactor is currently in state of stasis but the revitalization of the facility is in the long term roadmap for Department of Energy.

The TREAT reactor provides basic data for predicting the safety margin of fuel designs and the severity of potential accidents and serve as a proving ground for the design of new fuel concepts. The testing performed within TREAT reduces or precludes the consequent hazards associated with potential accidents. TREAT is an absolute necessity in the suite of reactor fuel test capabilities. Effective interpretation of TREAT experimental results defines the integrated understanding of fuel performance. The TREAT reactor has a steady state power capability of $100 \mathrm{~kW}$ steady, pulse half-width as low as $40 \mathrm{~ms}$, and a maximum transient power of 19,000 MW. The requirements placed on sensors and measurement architectures are significantly different for the transient treat reactor than a power reactor designed to run at steady state.

\section{F. Advanced Test Reactor}

The ATR National Scientific User Facility $[1,6]$ furnishes the unique test bed with controllable irradiation conditions and schedules that will enable users to test hypotheses in a true reactor environment. Users will be able to conduct the needed exploratory and confirmatory experiments for irradiation effects that help develop, validate, and bench mark measurements and predictive science for performance assessment and design. The availability of the ATR provides the unique capability of tying all of the measurement and experimental investigations to a true fission environment. The measurements initiative can leverage INL's long history and expertise in developing highly specialized instrumentation to meet demands of customers conducting unique tests in INL facilities.

\section{G. Modeling and Simulation}

Once the validated/calibrated data stream in from the ATR or other irradiation sources, data need to be fed into a feedback loop with Modeling and Simulation. The expertise and predictive models being developed at the Center for Materials Science of Nuclear Fuel [7] (and other centers) must be synergistically engaged with the measurements program to achieve the goal of developing and validating a computationally-predictive multi-scale understanding of nuclear fuel and materials: microstructure evolution under irradiation.

The two most critical issues limiting the performance and lifetime of the fuel are the degradation of the thermal conductivity of the fuel and the mechanical integrity of both the fuel and cladding. Particularly lacking is a comprehensive understanding how defect generation and evolution, as well as microstructure development during irradiation, affect the thermo-mechanical performance of the fuel. Thus, the development of in situ measurement capabilities to monitor degradation of critical components of the fuel assembly without the removal of material and subsequent destructive testing is critical to successfully achieving our goal of understanding microstructure evolution under irradiation.

\section{H. Controls}

Analogous to the synergistic engagement of modeling and simulation activities, instrumentation, control and intelligent systems activities need to be engaged in parallel. The combination of new real-time online sensors and greater fundamental understanding of fuel and materials behavior will allow for the development of novel and resilient control strategies. The development of these science-based technologies could lead to paradigm changing control methodologies that lead to more stable and longer life reactors by being able to directly monitor in situ measurements and microstructural changes.

\section{In Pile Sensor Technology}

The development of sensor technology for non-destructive and non-intrusive measurements in harsh environments is a very active field $[1,8,9]$. It is beyond the scope of this report to present a discussion of the available technologies. Several identified technologies that look promising include Optical fiber (including imaging), Ultrasonic, Ceramic microwave resonators, and Infrared-frequency selective resonators.

\section{SALIENT MEASURES}

A group from the FCRD Program composed of modelers, measurements, fuels, irradiation testing, and light water reactor personnel worked together to come to a consensus on a list of salient measures. The salient measures are intended to define objectives for in reactor measurements from a fuels perspective. The salient measures also identify the impact on the FCRD Program and our scientific knowledge of microstructure under irradiation. These priority-ordered measures are designed to coherently focus individual efforts that will maximize our understanding of the behavior of irradiated materials and advance the program's modeling effort. Other measurements should be pursued but are not initially emphasized.

\section{A. Thermal Properties}

Developing science based models of thermal transport will enable the prediction of degradation in thermal conductivity. A better understanding of the effect of irradiation induced microstructure evolution on thermal conductivity will improve 
prediction of fuel temperatures, leading to improved reactor safety and efficiency.

\section{B. Fission Gas Release}

Accurate science based models of fission gas release will enable the prediction of microstructure evolution that will lead to plenum pressure build up throughout the lifetime of the fuel. Once the science of fission gas release is understood, fuel microstructure can be designed to maximize fuel lifetime and reliability.

\section{Swelling}

Understanding the mechanics of swelling as a function of density changes due to bubbles and cracks will lead to a fundamental understanding of fuel microstructure changes that control fission gas and volume changes. Fuel microstructure changes can then be controlled to limit deleterious fuel cladding interactions and pin failure.

\section{Crack Growth}

Determining crack propagation mechanisms and paths in fuel microstructure may reveal drastically different physics in fresh versus irradiated fuel. Thus, safety margins can be specified for different stages of fuel burn up, which will lead to greater efficiency and operating life.

\section{E. Mass Transport / Diffusion}

Understanding the root cause of and predicting the time dependence of species transport is essential for both oxide fuels (oxygen transport leading to variations in off stoichiometry) and metallic fuels (species redistribution leading to non uniform heat generation). Accurately modeling the rate of these transport processes will allow improved reactor safety and efficiency.

\section{SUMMARY}

The first requirement of any in-pile sensor is the need to effectively communicate with the outside world. The sensors may require an in situ power source and radiation/thermal hardened components to efficiently transmit information. To make sure that the measurements are accurate and not confounded by multiple environmental phenomena, facilities like SETFBLS and TREAT will be needed to perform separate effects and robustness testing on the sensors. A test reactor facility like the ATR is necessary to understand the performance of the sensors and degradation effects within an actual reactor core. Once the measured data have been proven robust, the knowledge base of microstructure evolution will increase enabling better models to be developed that effectively predict the behavior of materials under irradiation. The accurate prediction of material behavior within a reactor will permit the advancement of resilient control technology to help control the path of the microstructure evolution.

The five salient measures that should be the initial focus of sensor development are

1. Thermal properties
2. Fission gas release

3. Swelling

4. Crack growth

5. Mass transport/diffusion.

These are the measures, determined via a consensus, which will expediently enhance the knowledge of microstructure under irradiation. These five measures will enable predictive models in a timely manner.

Successful development and in situ power generators for sensing and actuations applications would represent significant, if not revolutionary, advancements. The measurements and control infrastructure must be able to evolve fuel/material microstructure with a prescribed in situ process to achieve maximum knowledge and performance.

\section{ACKNOWLEDGMENT}

The authors would like to thank the following for their input: Joe Palmer, Tony Hill, Eric Burgett, Paul Millett, Michael Tonks, Steve Hayes, Jon Carmack. This manuscript has been authored or co-authored by Battelle Energy Alliance, LLC under Contract No. DE-AC07-05ID14517 with the U.S. Department of Energy. The United States Government retains and the publisher, by accepting the article for publication, acknowledges, that the United States Government retains a nonexclusive, paid-up, irrevocable, world-wide license to publish or reproduce the published form of this manuscript, or allow others to do so, for United States Government purposes.

\section{REFERENCES}

[1] INL/EXT-09-16392, "New in-pile instrumentation to support Fuel Cycle Research and Development," http://www.inl.gov/technicalpublications/Documents/4781572.pdf.

[2] Idaho Joint Research Center, http://commerce.idaho.gov/news/2011/05/on-donates-5-million-inequipment-to-isu.aspx.

[3] Idaho Joint Research Center, http://www.isu.edu/newsandnotes/110815/grant.shtml.

[4] INL/EXT-09-16392, "Future transient testing of advanced fuels," http://www.inl.gov/technicalpublications/Documents/4480294.pdf.

[5] D. C. Crawford, "Experimental capabilities of the transient reactor test (TREAT) facility," 1998 ANS Winter Meeting Nov 15-19 1998, Jul 1998.

[6] INL/EXT-08-14709, "FY2009 Advanced Test Reactor National Scientific User Facility User's Guide," https://secure.inl.gov/atrproposal/documents/ATRUsersGuide.pdf.

[7] Center for Materials Science of Nuclear fuel, https://inlportal.inl.gov/portal/server.pt/community/center_for_materials _science_of_nuclear_fuel $/ 655 / \mathrm{home}$.

[8] J. L. Rempe, D. L. Knudson, K. G. Condie, J. E. Daw, H. Ban, B. S. Fox, and G. E. Kohse, "New Sensors for the Advanced Test Reactor National Scientific User Facility" invited paper for ANIMMA Special Edition, IEEE Transactions on Nuclear Science, Vol. 57, Iss. 5, pp. 2653 - 2661, October 2010.

[9] J-F Villard and M. Schyns, "Advanced In-Pile Measurements of Fast Flux, Dimensions, and Fission Gas Release," Proceedings of the ANS NPIC HMIT 2009 Topical Meeting on Nuclear Plant Instrumentation, Controls, and Human Machine Interface Technology, Knoxville, TN, April 2009. 